\title{
Pilot Scale Advanced Fogging Demonstration
}

Rick L. Demmer

Don T. Fox

Kip E. Archibald

January 2015

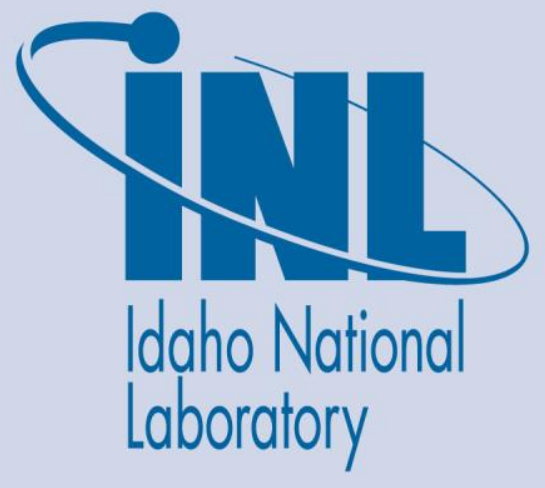

The INL is a U.S. Department of Energy National Laboratory operated by Battelle Energy Alliance 


\section{DISCLAIMER}

This information was prepared as an account of work sponsored by an agency of the U.S. Government. Neither the U.S. Government nor any agency thereof, nor any of their employees, makes any warranty, expressed or implied, or assumes any legal liability or responsibility for the accuracy, completeness, or usefulness, of any information, apparatus, product, or process disclosed, or represents that its use would not infringe privately owned rights. References herein to any specific commercial product, process, or service by trade name, trade mark, manufacturer, or otherwise, does not necessarily constitute or imply its endorsement, recommendation, or favoring by the U.S. Government or any agency thereof. The views and opinions of authors expressed herein do not necessarily state or reflect those of the U.S. Government or any agency thereof. 


\title{
Pilot Scale Advanced Fogging Demonstration
}

\author{
Rick L. Demmer \\ Don T. Fox \\ Kip E. Archibald
}

January 2015

Idaho National Laboratory Idaho Falls, Idaho 83415

http://www.inl.gov

Prepared for the

U.S. Department of Energy

Office of Environmental Management

Under DOE Idaho Operations Office

Contract DE-AC07-05ID14517 



\section{SUMMARY}

Experiments in 2006 developed a useful fog solution using three different chemical constituents. Optimization of the fog recipe and use of commercially available equipment were identified as needs that had not been addressed. During 2012 development work it was noted that low concentrations of the components hampered coverage and drying in the United Kingdom's National Nuclear Laboratory's testing much more so than was evident in the 2006 tests.

In fiscal year 2014 the Idaho National Laboratory undertook a systematic optimization of the fogging formulation and conducted a non-radioactive, pilot scale demonstration using commercially available fogging equipment. While not as sophisticated as the equipment used in earlier testing, the new approach is much less expensive and readily available for smaller scale operations. Pilot scale testing was important to validate new equipment of an appropriate scale, optimize the chemistry of the fogging solution, and to realize the conceptual approach. 


\section{CONTENTS}

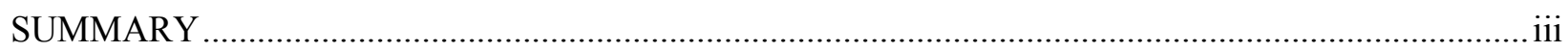

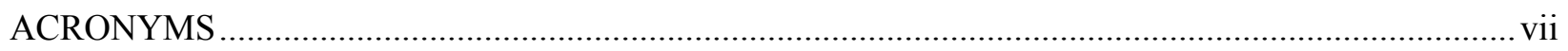

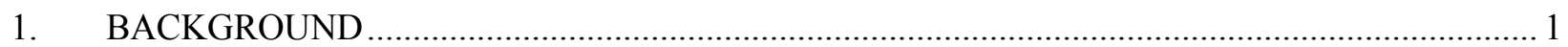

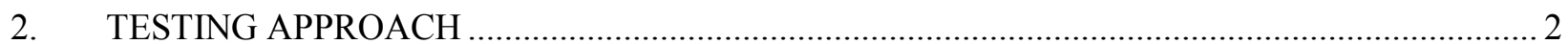

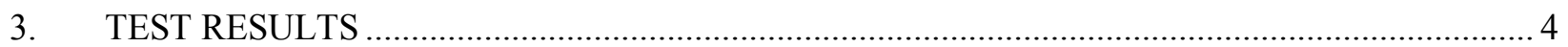

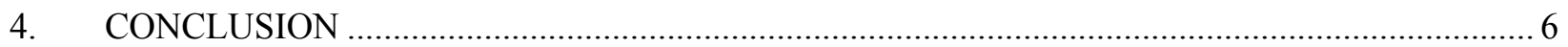

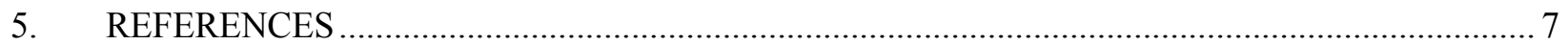




\section{ACRONYMS}

BCTC Bonneville County Technology Center

D\&D Decommissioning and demolition

DOE Department of Energy

EM DOE Office of Environmental Management

FY fiscal year

GLY glycerin, a coagulant

INL Idaho National Laboratory

LTX latex paint, a binder

NFPA National Fire Protection Association

NNL United Kingdom's National Nuclear Laboratory

SLS sodium lauryl sulfate, a surfactant 


\section{BACKGROUND}

Radiological contamination control is crucial during decommissioning and demolition (D\&D) activities, as well as during modifications to existing radiological systems. It is well known that contamination, in some cases substantial contamination, is present throughout the exhaust ductwork in several older processing facilities within the Department of Energy (DOE) complex, due to years of processing radioactive materials in areas served by closed ventilation systems. Accumulations of radioactive dust and lint - commonly found in laundry facilities, exhaust ventilation ducting, and exhaust stacks - present a specific contamination control issue. Particle suspension is more likely to occur during cleaning, modification, or demolition of these systems and during disposal site exhumation. In a recent demolition of large ventilation ducting $\left(\sim 10^{\prime} \times 10^{\prime}\right.$ cross section, $\sim 100^{\prime}$ long $)$ at Brookhaven National Laboratory, a spray coating was manually applied to the inside of the duct - requiring painters, dressed in anti-contamination clothing and an airline respirator system, to enter the duct. ${ }^{1}$ The advanced fogging technique offers an alternative method to mitigate these airborne contamination hazards with minimal personnel entry.

In 2006, a DOE Small Business Innovation Research grant resulted in the development of a conceptual advanced capture coating fog system. In those 2006 tests, the coating was shown to be superior to other commercial fogging agents at reducing airborne contamination and affixing it in place. Twenty-five different solutions were tested. The best performer was a solution that contained a latex binder, a surfactant, and a coagulant that combine to make the fogging solution "wetter". It penetrated dusty contaminants and bound them into a film. ${ }^{2}$ In 2012 and 2013 the Idaho National Laboratory (INL) and the United Kingdom's National Nuclear Laboratory (NNL) collaborated to show that a large scale application of the fog was possible using PDx's Aerosonix pneumatic dispersion atomizer. ${ }^{3}$ See Figure 1. Unfortunately, PDx went out of business in early 2013, forcing NNL to resort to a less sophisticated fogging unit. Late in fiscal year (FY) 2013, an additional $\$ 200,000$ was allocated to continue the 2012

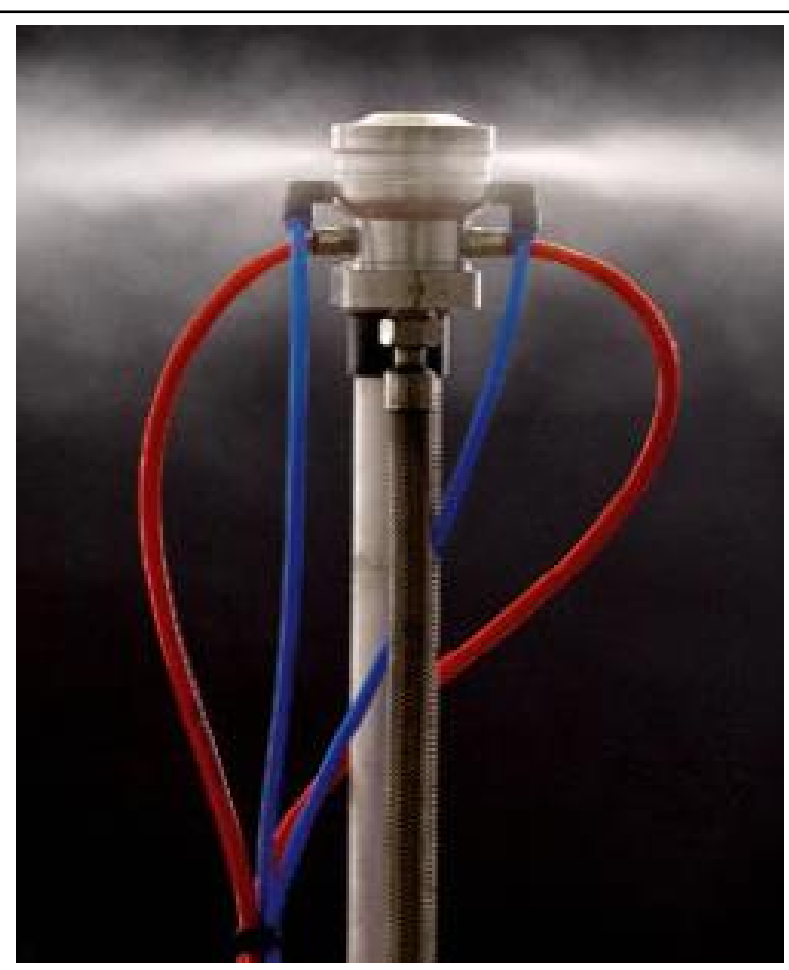

Figure 1. PDx $360^{\circ}$ Aerosonix atomizer. development efforts. Those funds were used in FY 2014 to conduct pilot scale testing of the fogging process and to optimize the fogging solution recipe.

In the 2006 experiments a useful fog solution had been developed using three different chemical constituents. This early work had not optimized the percentages of these components. Optimization of the fog recipe and use of commercially available equipment were identified in the 2006 report as needs that had not been addressed. ${ }^{2}$ During the 2012 development work we noted that low concentrations of the components had hampered coverage and drying in NNL's testing much more so than was evident in the 
earlier work. ${ }^{4}$ Some reformulation was undertaken at that time, increasing the concentration of the latex binder above $10 \%$.

\section{TESTING APPROACH}

In FY' 14 the INL undertook a systematic optimization of the fogging formulation and conducted a non-radioactive, pilot scale demonstration using commercially available fogging technology. While not as sophisticated as the PDx (nor NNL) equipment, the new approach is much less expensive and readily available for smaller scale operations. The bench top system used in earlier testing (see Figure 2) was capable of delivering $\sim 0.010$ liters per minute of fog solution. The PDx system produced $\sim 5$ liters per minute. The commercial fogger used in the FY' 14 INL tests produces $\sim 0.3$ liters per minute.

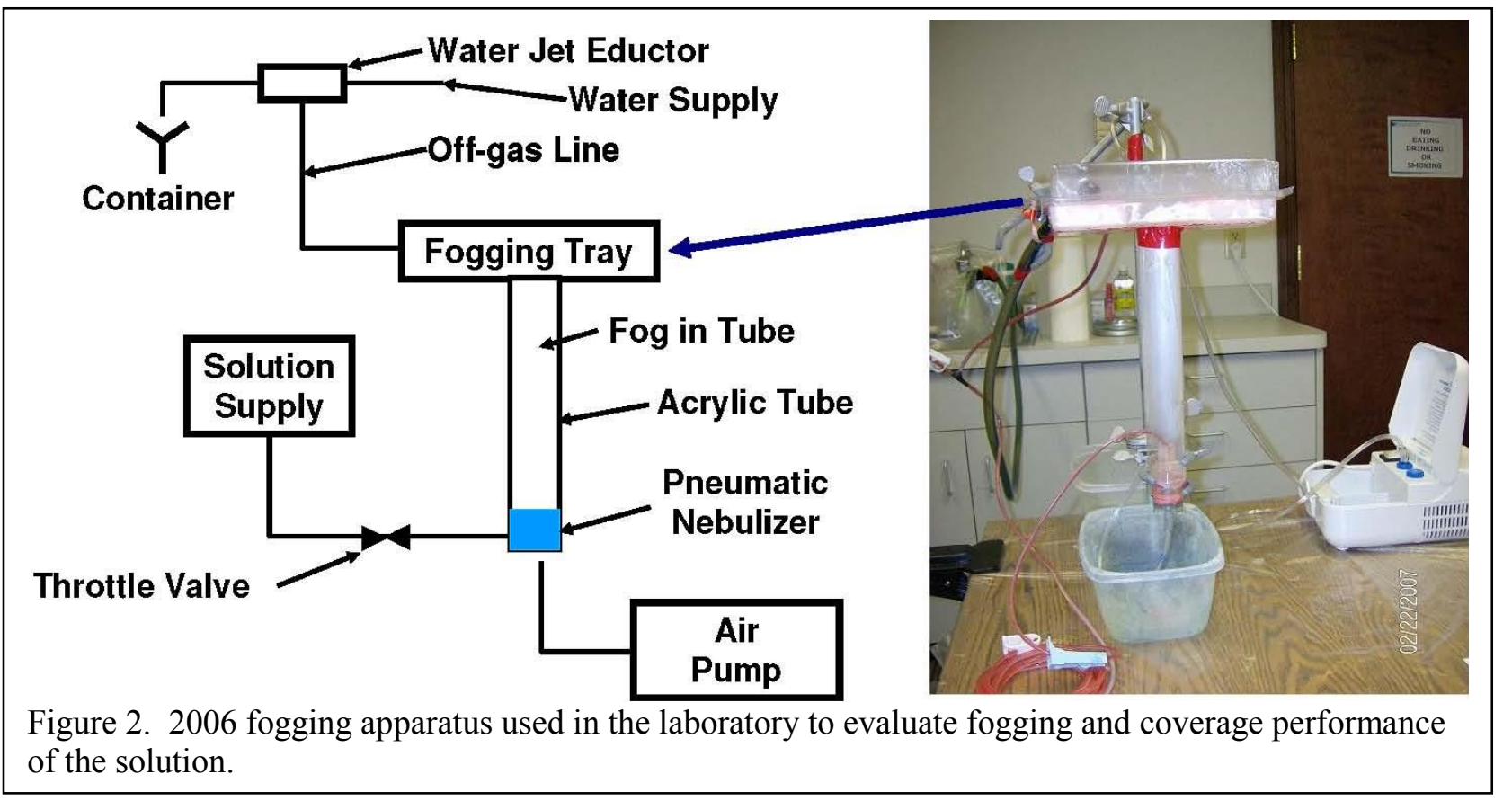

FY'14 efforts at INL included preparing a test plan and safety documentation in order to construct and operate the pilot scale fogging enclosure. ${ }^{5}$ The enclosure, shown in Figure 3, is $2.5 \times 2.5 \mathrm{~m}$ and $\sim 2 \mathrm{~m}$ high at the roof peak. It was equipped with sample ports and gloves for remote access. The purpose of this chamber was to contain the low pressure $(<10 \mathrm{psi})$ fogging solution. Personnel worked from outside the chamber. The enclosure was constructed using commercially available flame retardant polyethylene sheeting (6 mil Americover) with a plastic support frame (in accordance with NFPA 701-04). A commercially available, intrinsically safe (explosion proof) ventilation fan (Larson Electronics model EPF-10P.3, [MagnaLight.com]), connected through ductwork and air filters, provided a slight negative pressure on the enclosure, preventing release of the fog outside of the enclosure.

Mixtures of water, latex paint (LTX), glycerin (GLY), and sodium lauryl sulfate (SLS) were tested in the enclosure. The fractional factorial method was employed to minimize the number of combinations that had to be tested in order to arrive at an optimum formulation. In this method a conceptual box is constructed using the high and low concentrations of the different constituents. Concentrations are expressed (for the factorial table) as "+" (high) or "_" (low). The results are tabulated and compared in a 
relative manner and an arithmetic model is constructed to determine the optimum concentrations. ${ }^{6}$ About 2.5 liters of each solution was prepared. Concentrations ranged from 5-25\% for LTX, and 3-10\% for SLS and GLY. Due to the factorial approach, only four mixtures were needed. Each test required about four hours to prepare and conduct, followed by a drying time of 1-3 days. Test 1 (R1), an operational test of the equipment, was not used for comparison purposes.

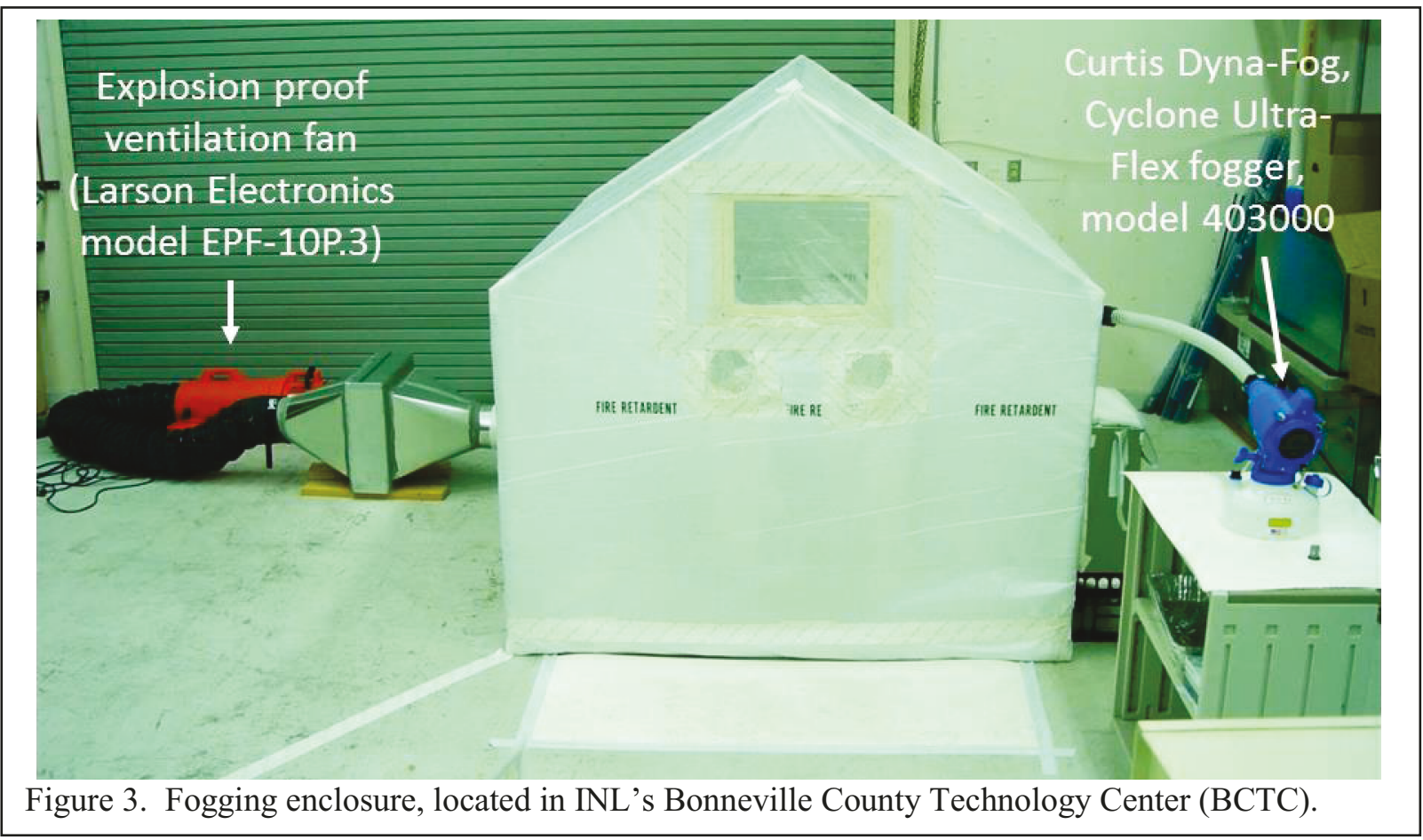

Talcum powder placed in a small plastic dish and thin and thick polypropylene cloth/batting coupons cut into $10 \mathrm{~cm}$ squares were used to evaluate the performance of the test solutions. The talcum powder was used to determine dustiness after fogging (i.e., assess the ability of the solution to affix fine particulate to a surface), and the polypropylene coupons evaluated penetration of the fog into a matrix.

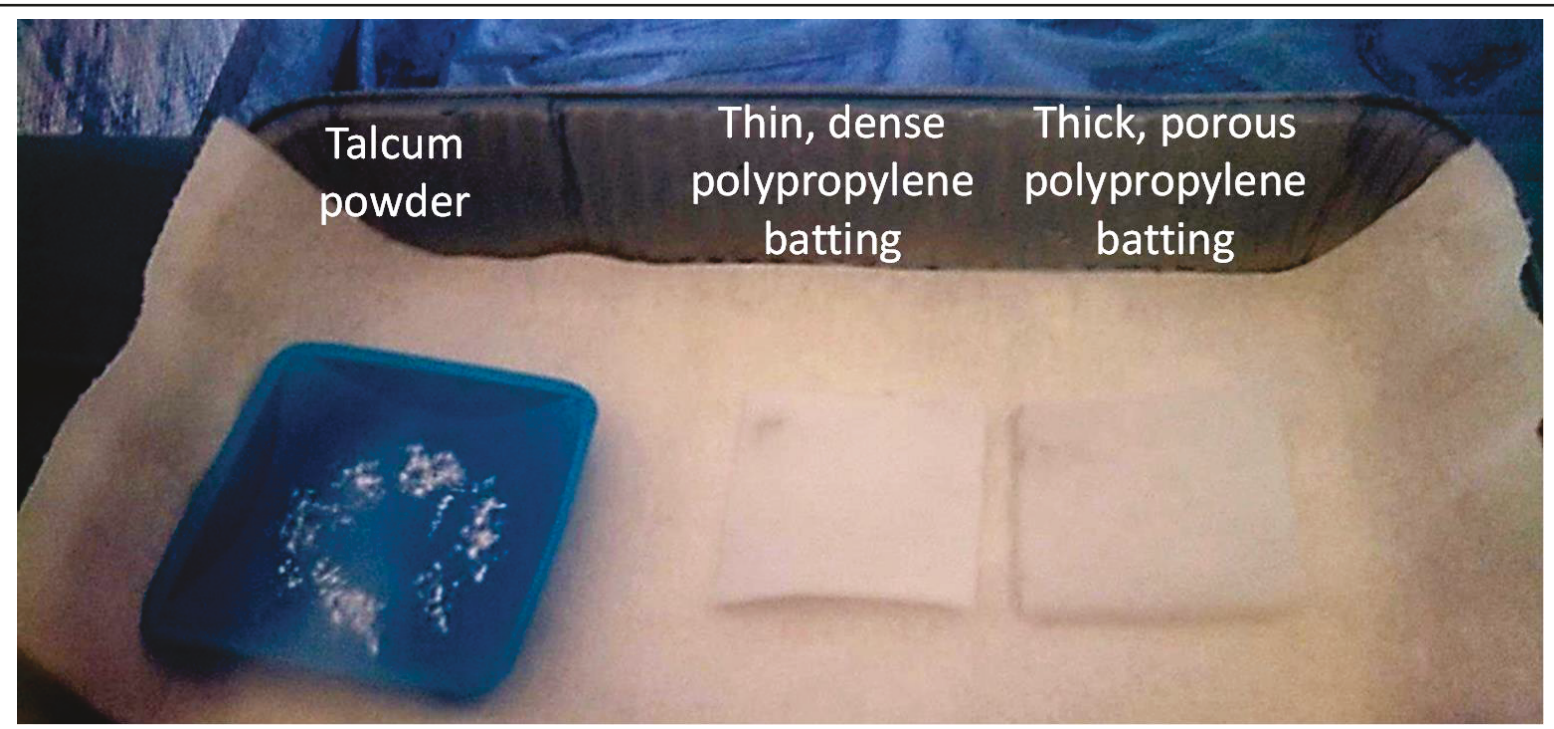

Figure 4. Test materials prior to fogging. 
The thin batting allowed the fog to penetrate less than the thick (more porous) material. Pictures of these materials prior to fogging are shown in Figure 4.

Test solutions were prepared by weight, thus a 2.5 liter batch used at most 250 grams of powdered (10\%) sodium lauryl sulfate, for example. The viscosity of each solution was tested using a paint cup type viscometer. The solution was then loaded into the reservoir of the fogger (Curtis Dyna-Fog, Cyclone Ultra-Flex, model 403000). The fogger operated for about 15 minutes (or until the solution ran to a predetermined value). During this timed run, the exhaust blower operated for 20 seconds every two minutes to maintain a slight negative pressure inside the enclosure. At the end of the run, the enclosure was allowed to exhaust completely through the filter and blower, then opened to remove the samples.

\section{TEST RESULTS}

The results from the pilot scale tests yielded an optimized recipe for the fogging solution. The latex paint was originally set at a low level of about $10 \%$, but the NNL tests indicated that a higher concentration was necessary. The optimization tests confirmed these results. While the bench top tests did not require the level of binder (latex paint) arrived

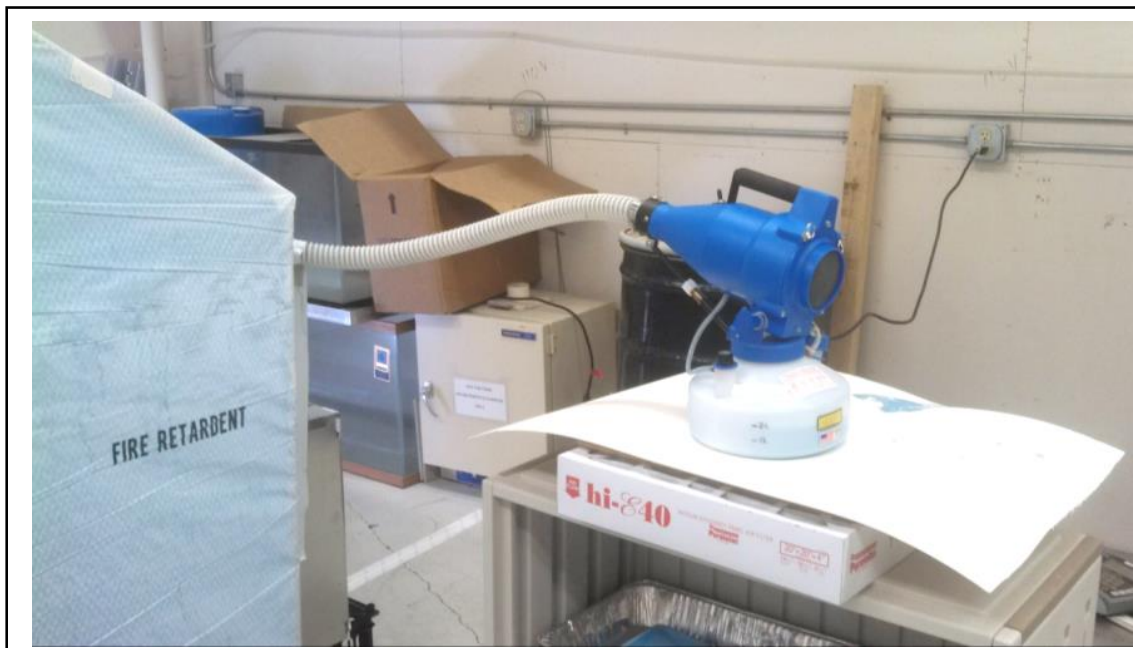

Figure 5. Curtis Dyna-Fog Cyclone used in the pilot scale fogging tests. at in the optimization study, that was likely a result of the small scale and very dry conditions experienced during the majority of those tests. As noted in the previous report, the NNL tests occurred at a lower

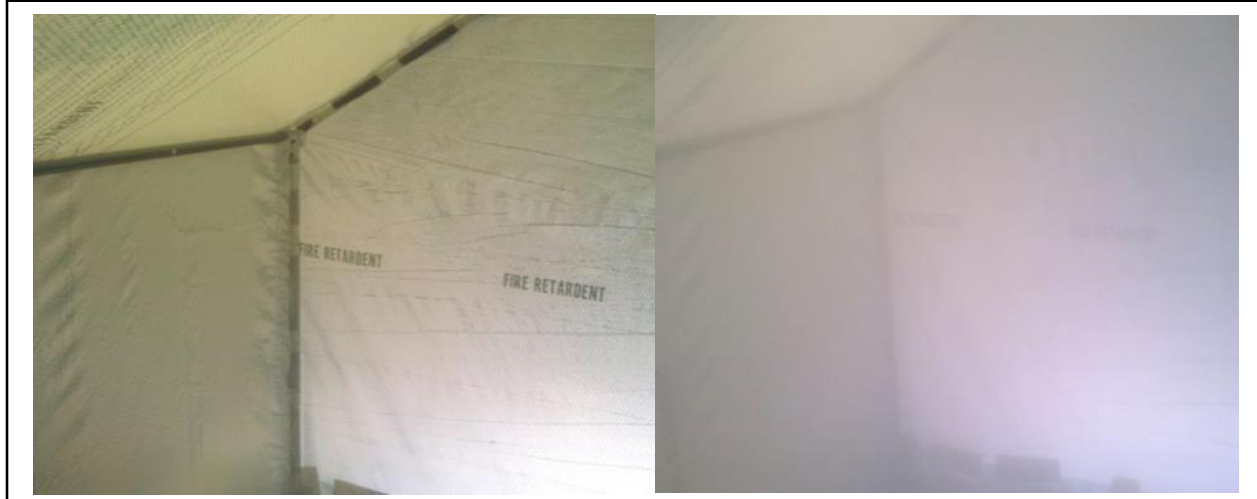

Figure 6. Before (left) and during (right) fogging in the enclosure. temperature $\left(16^{\circ} \mathrm{C}\right.$ vs. $21^{\circ} \mathrm{C}$ ) and at much higher relative humidity (90\% vs. $15 \%) .{ }^{4}$ Temperature and humidity affect the drying rate of the fog, as they do with any water based solution. Rapid drying (typically within 24 hours) is a major criterion for a

useful, deployable fogging process. 
Table 1. Fractional Factorial Fog Test Data

\begin{tabular}{|c|c|c|c|c|c|c|c|}
\hline Run & $\begin{array}{c}\text { Data } \\
\text { ID }\end{array}$ & $\begin{array}{c}\text { SLS } \\
\text { (wt. \%) }\end{array}$ & $\begin{array}{c}\text { GLY } \\
\text { (wt. \%) }\end{array}$ & $\begin{array}{c}\text { LTX } \\
\text { (wt. \%) }\end{array}$ & Coverage & Penetration & Dustiness \\
\hline R2 & y5 & $3(-)$ & $3(-)$ & $25(+)$ & 70 & 30 & 40 \\
\hline R3 & y2 & $10(+)$ & $3(-)$ & $5(-)$ & 40 & 90 & 30 \\
\hline R4 & y3 & $3(-)$ & $10(+)$ & $5(-)$ & 30 & 70 & 70 \\
\hline R5 & y8 & $10(+)$ & $10(+)$ & $25(+)$ & 90 & 70 & 90 \\
\hline
\end{tabular}

Testing in the enclosure proves the new fogging equipment is viable as a demonstration device. The Curtis Dyna-Fog Cyclone (Figure 5) produced a large amount of fog in a very short time in the $\sim 9 \mathrm{~m}^{3}$ test enclosure, with no operational issues and at a minimal cost. The unit costs $\sim \$ 600$. Droplet size is within the fog range $(5-30 \mu \mathrm{m})$, allowing the mixture to move like a gas - which is the key attribute for fogging applications. Pictures taken looking through the window of the enclosure (Figure 6) show the development of a thick fog in the enclosure during testing. This size unit would be applicable to a small $(\sim 6 \mathrm{~m} \times 6 \mathrm{~m})$ room, hot cell, or airlock. Curtis also produces a larger portable unit (model L-15) that is capable of producing fog at 6 times $(\sim 1.8 \mathrm{~L} / \mathrm{min}$.) the rate of the Cyclone model. While not as prolific as the Aerosonix fogger ( $\sim 5 \mathrm{~L} / \mathrm{min}$.), the L-15 is certainly capable of producing enough fog for a large room application, and multiple fogger configurations would facilitate much large applications.

Table 2. Each Component's Effect on Fog Quality

\begin{tabular}{|c|c|c|c|}
\hline $\begin{array}{c}\text { Component } \\
\text { Tested }\end{array}$ & Dustiness & Penetration & Coverage \\
\hline SLS & 5 & 30 & 5 \\
\hline GLY & 45 & 10 & 15 \\
\hline LTX & 15 & -30 & 45 \\
\hline
\end{tabular}

The coupons and powder were analyzed for relative performance of the fog solutions with respect to the criteria of dustiness, penetration, and coverage. They were judged in these categories in a relative fashion, with each coupon or powder specimen being rated from 30 to 90 depending on how well they met the desired characteristics. The best overall recipe is $10 \%$ SLS, $10 \%$ GLY, and $25 \%$ LTX (i.e., the most concentrated of the four solutions) - evident in the rankings shown in Table 1. Dustiness was qualitatively evaluated by the ability of the fog, once dry, to encapsulate talcum powder in a $100 \mathrm{~cm}^{2}$ weighing dish and to maintain immobilization of the powder when being rubbed and inverted. Penetration of the fog was judged by the relative depth the fog penetrated into the central portion of the batting coupons. Photomicrographs showing the relative extent of coverage and penetration into the thicker, less dense polypropylene pads are shown in Figure 7. In these images it is clear that the solution (blue color) was held in the upper $1 \mathrm{~mm}$ of the surface of R2 (upper left pane of Figure 7), while it penetrated three times deeper (perhaps more) in R3 (upper right pane of Figure 7). The coverage of the surface was more difficult to judge, as some coupons had depth of penetration (desirable), while others 
had only superficial coverage. The stickiness (good) and oiliness (bad) of the solution played a role in determining the quality of the fog.
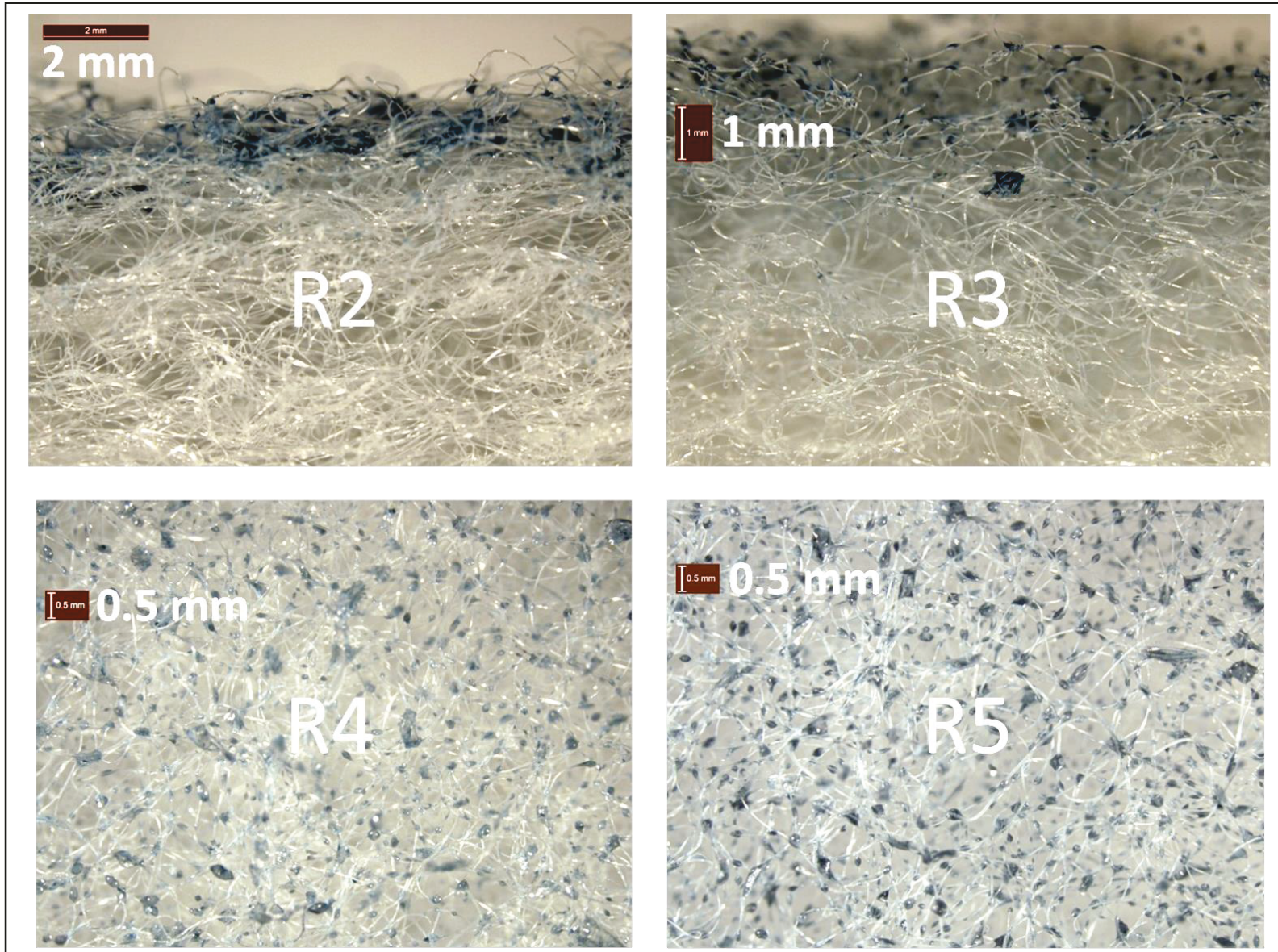

Figure 7. Upper: Micrographs comparing fog penetration in test R2 (upper left) and R3 (upper right). A cross section view is shown. The fog solution is blue in color.

Lower: Micrographs showing surface coverage for test R4 (lower left) versus test R5 (lower right). An overhead view is shown. Note that R5 has a thicker, higher density of blue globules than R4.

Fractional factorial analysis of the data from Table 1 shows each component of the solution was most responsible for the mixture's performance against one criterion.. Each component's contribution is reduced by an algorithm (e.g., X1 $=$ SLS effect $=1 / 2[\mathrm{y} 2+\mathrm{y} 8]-1 / 2[\mathrm{y} 5+\mathrm{y} 3])$ which yields the most pronounced effect shown by variation in that factor. ${ }^{6}$ Coverage is driven primarily by the concentration of latex (binder), especially if higher concentrations of glycerin (coagulant) or sodium lauryl sulfate (surfactant) are used. Glycerin most influenced dust immobilization: the higher the glycerin concentration, the more encapsulating and cohesive is the dried coating. Latex concentration also had a significant effect on this criterion. Penetration below the surface was dramatically improved by increased levels of surfactant (and hampered by higher latex paint concentrations). See Table 2.

\section{CONCLUSION}

The FY'14 experiments have produced an optimized fogging solution and a deployable implementation of this technology that can be used in more refined demonstrations. In previous testing, 
both at the INL and NNL, the fogging solution was adequate, but some manipulation of the components was typically required. A basis for the formulation, along with defensible testing of an optimized formula, has now been developed. In addition to optimizing the formulation, we have determined which chemicals are responsible for each effect, which will facilitate fine tuning of the solution for individual applications.

This set of experiments also validated the approach of using an inexpensive, unsophisticated fogger and a portable blower to control the buildup of the fog. Previously it was thought that more sophisticated equipment would be required, thus significant resources were devoted to the testing, selection, and fabrication of that equipment. However, a fogger that produces the proper droplet size (per its specification) was commercially available at an inexpensive price. Fielding this approach, equipment, and chemistry is the next step for the project. Several sites/facilities have expressed an interest in this process. Discussions are underway to identify an appropriate venue for field application.

Two other development avenues are also underway. One is a trial of an offshoot of this technology which employs a mercury absorbent. Preliminary results have been positive. A second, as yet unexplored, line of inquiry is to produce a strippable decontamination coating applied by the fogging method.

\section{REFERENCES}

1. “Visible Progress Made as BNL's Skyline Changes", Cleanup Update, US DOE/ Brookhaven National Laboratory, September 2000.

2. L.M. Kostelnik, J.R. Kriskovich, J.W. Maresca, Jr., J.L. Tripp, R.L. Demmer, “An Improved Fogging Method to Prevent the Release of Airborne Radionuclide Contamination from Ductwork During Decontamination \& Decommissioning”, Paper No. 8287, WM2008 Conference, Phoenix, AZ, February 24-28, 2008.

3. A. Banford, R. Demmer, J. Edwards, R. Rankin, J. Hastings, "INL-NNL an International Technology Collaboration Case Study - Advanced Fogging Technologies for Decommissioning," Paper No. 13463, WM2013 Conference, Phoenix, AZ, February 24-28, 2013.

4. R.L. Demmer, "Fixation of Radiological Contamination: International Collaborative Development," INL/EXT-13-28708, March 2013.

5. INL Laboratory Instruction 1705-LI-BCTC, Advanced Fogging Technology Research, Rev. 2, May 2014.

6. V. Nair, Univ. of Michigan, URL: dept.stat.lsa.umich.edu/ samurphy/nida/seminars/ffd-tutorial.ppt 